\title{
NOTAS
}

\section{Cien años de soledad y la tradición de la biografía imaginaria}

Aunque Cien años de soledad, 1 la extraordinaria novela de García Márquez, es algo más que la "biografía novelesca" del coronel Aureliano Buendía, es bien sabido que el impulso original que puso en marcha la obra fue el deseo de contar la historia, a la vez individual y alegórica, de un personaje que se basaba en el abuelo materno del autor. Esa "biografía" habría de transformarse en toda una saga familiar, y el coronel Buendía llegaría a ser sólo uno entre los numerosos personajes centrales de la novela. Aún así, es indudable que resulta de la mayor importancia crítica estudiar el modelo biográfico del que parte García Márquez para llegar a la saga familiar.

En su entrevista con Luis Harss (que está reproducida en el libro Los nuestros, de este crítico), García Márquez ha indicado una de las fuentes para ese modelo biográfico inicial: el Orlando, de Virginia Woolf, $y$ ha dicho que en los escritos de la novelista inglesa ha encontrado "un estilo y un arte": 2 Por su parte, Emir Rodríguez Monegal ha indicado algunos rasgos que vinculan la novela de García Márquez con la "biografía" de Mrs. Woolf. Esos rasgos podrían sintetizarse así: la presentación de un personaje imaginario, que vive más de cuatrocientos años y cambia de sexo a la mitad de su vida, como si fuera un personaje real;

1 Gabriel García Márquez: Cien años de soledad. Buenos Aires. Editorial Sudamericana, 1967. Las citas se harán por la 5a cdición, de 1968.

2 Luis Harss: "García Márquez o La cuerda floja", en Mundo Nuevo, No 6, París, diciembre 1966, p. 68. El artículo está recogido en: Luis Harss y Barbara Dohmann: Lo's nuestros. Buenos Aires: Editorial Sudamericana, 1966. 
el viaje a través de los tiempos y espacios, de las distintas culturas y estilos de vivir; la sátira o parodia de géneros literarios del realismo; el humor que llega a la sátira y a la hipérbole. ${ }^{3}$

La obra de Mrs. Woolf fue publicada en Inglaterra en 1928. Una versión castellana de la misma, a cargo de Jorge Luis Borges, fue publicada en la Argentina en 1937. Es más que probable que García Márquez haya leído Orlando en la traducción de Borges. Si es así, debió haber asimilado "el estilo" y "el arte" de la escritora inglesa a través del me. dio que constituye el lenguaje de Borges. La traducción del narrador argentino es, en muchos casos, más concisa e imaginativa que el mismo original. Para dat un ejemplo, Borges traduce "...grins at him... triumphantly" por "le hacía muecas triunfales", que elimina la pesadez del sufijo adverbial en "mente" y crea una imagen más llamativa al yuxtaponer dos palabras enfáticas: "muecas" y "triunfales".

En otro lugar he tenido oportunidad de examinar con cierto detalle las relaciones entre el Orlando y Cien años de soledad desde el punto de vista del modelō biográfico. Ahora quisiera estudiar la importancia de la traducción de Borges, y la influencia que su obra narrativa original puede haber tenido sobre Ta novela de García Márquez. Para ello es necesario realizar una excursión que nos llevará del Orlando a un par de obras que son prototipos de la biografía imaginaria, para volver luego a Cien años de soledad.

\section{EL PRIMER LECTOR HISPÁNICO}

Aún antes de publicar su traducción de Orlando, Borges había llamado la atención sobre la obra entera de Mrs. Woolf. En la sección "Libros y Autores Extranjeros" con que colaboraba quincenalmente en el semanario $E l$ Hogar, de Buenos Aires, Borges incluye una "biografía sintética" de Virginia Woolf, que es modelo de concisión. Dicha "biografía" se completaba con la traducción de un pasaje de Orlando. Era la primera vez que la prosa de Mrs. Woolf aparecía metamorfoseada en

\footnotetext{
${ }^{3}$ Emir Rodríguez Monegal: "Novedad y anacronismo de Cien años de soleaad", en Revista Nacional de Cultura, Año XXIX, No 185, Caracas, julio-agostoseptiembre, 1968. pp. 3-21.

4 Virginia Woolf: Orlando. Traducción de Jorge Luis Borges. Buenos Aires: Editorial Sur, 1937. Las citas se harán por la reedición: Buenos Aires, Editorial Sudamericana, 1968, p. 11. En la edición norteamericana (New York, Harcourt, Brace \& World, 1928), el texto citado está en la p. 14.
} 
castellano por Borges. Posteriormente, y a pedido de Victoria Ocampo, Borges tradujo el libro entero.

En su "biografía sintética", Borges escribe sobre Orlando:

En Orlando también hay la preocupación del tiempo. El héroe de esa novela originalísima — sin duda de las más singulares y desesperantes de nuestra época- vive trescientos años y es, a ratos, un símbolo de Inglaterra y de su poesía particular. La magia, la amargura y la felicidad colaboran en ese libro. Es además, un libro musical, no solamente por las virtudes eufónicas de su prosa, sino por la estructura misma de su composición hecha de un número limitado de temas que regresan y se combinan.

Es posible suponer que fue Borges el que atrajo la atención de los lectores latinoamericanos sobre el estilo de Virginia Woolf, y no sólo por medio de sus escritos críticos o por su traducción, sino también por la evidencia de sus propios cuentos, en donde es posible encontrar huellas del estilo también empleado en la traducción de Orlando.

Así, por ejemplo, la Historia Universal de la Infamia (1935), el primer libro de ficción publicado por Borges, es un conjunto de biografías que se basan en personajes históricos reales, aunque oscuros o controvertidos. ${ }^{6}$ Como en Orlando, el libro de Borges ficcionaliza la historia, o (tal vez) simplemente sitúa personajes casi totalmente ficticios en un contexto histórico preciso. Este empleo inesperado de la fantasía sorprende, y hasta cierto punto, sacude muestra sensibilidad. Al mismo tiempo, en otro sentido, sirve mejor a los fines de la sátira, propósito que se apunta en el título, subrayadamente hiperbólico, de la obra de Borges. Para alcanzar mejor la verdad que esconden estos personajes semi-históricos, Borges se sirve de procedimientos descaradamente ficticios. La sátira resulta así reforzada. Así como Virginia Woolf en su Orlando se burla, por ejemplo, del progreso tecnológico del siglo xIx, al mostrarlo a través de los ojos ingenuos de Orlando, nacido y educado en la Inglaterra de Isabel I, Borges desmitifica ciertas figuras legendarias como

5 Jorge Luis Borges: "Libros y Autores Extranjeros: Biografías sintéticas: Virginia Woolf", en El Hogar, Buenos Aires, 30 de octubre de 1936, p. 25. Esta cita ha sido utilizada en la tapa posterior de la reedición argentina, ya citada, de Orlando.

6 Jorge Luis Borges: Historia Universal de la Infamia. Buenos Aires: Colección Megáfono, 1935. Hay reedición en las Obras Completas, de Jorge Luis Borges: Volumen III, Buenos Aires: Emecé Editores, 1954. Las citas se harán por la sexta impresión, de 1966. 
Billy the Kid, al llamarlo por su verdadero nombre, Bill Harrigan, y comentar algo secamente: "Nunca se pareció del todo a su leyenda, pero se fue acercando". De todas maneras, la desmitificación, si bien es irónica, no es total: en el mismo relato Borges demuestra que si el verdadero Billy the Kid no alcanzó al mito, la verdad esı que mató a muchos hombres, "sin contar mejicanos"."

\section{UN MODELO FRANCÉS}

Para entender mejor la novedad de Borges, se hace necesario retroceder un poco más, hasta uno de los libros que indudablemente ha servido de fuente a la Historia Universal de la Infamia, y tal vez hasta al Orlando. Se trata de las Vies imaginaires, de Marcel Schwob (1921). Las Vidas imaginarias fueron traducidas al español por Ricardo Baeza y publicadas en Buenos Aires, en 1943. La traducción debe haber sido bastante popular en su tiempo, aunque no se ha reeditado. De todas maneras, aunque es posible suponer que García Márquez nunca leyó este libro, su influencia pudo haberle llegado a través de la Historia de Borges, que se reeditó en 1954.

Como en este libro, Schwob recoge en el suyo las biografías de algunos personajes realmente históricos, pero de los que no se sabe mucho. Aunque conviene aclatar que su elenco es más variado e ilustre que el de Borges. Pero lo más importante del libro francés es el enfoque y el estilo. Schwob se apoya en la retórica clásica y abunda en eufemismos y alusiones; su estilo es consistentemente elegante, y difiere mucho, por eso mismo, de los estilos más incisivos, y a veces secos, de Virginia Woolf y Borges. Estos están más cerca de la tradición neoclásica de Edward Gibbon. Cuando Mrs. Woolf, o Borges, usan el lenguaje eufemístico, es más para subrayar la ironía que para afectar elegancia. De ahí que pueda afirmarse que Schwob anticipa a ambos escritores, sobre todo en su enfoque de la biografía imaginaria.

Ya Roger Caillois ha llamado la atención sobre da importancia de Schwob en la obra de Borges. Como apunta el profesor James E. Irby, al comentar uno de los cuentos de la Historia:

Caillois sugiere otro modelo: Marcel Schwob, cuyo "Roi au masque d'or" tiene un rostro leproso debajo de una máscara enjoyada, si-

7 Op. cit., "El asesino desinteresado Bill Harrigan", p. 65. La cita anterior se encuentra en la p. 70. 
milar a la del Profeta velado de Jorasăn, y cuyas Vies imaginatres tiene como prefacio esta observación: "El arte del biógrafo consiste precisamente en saber elegir. No tiene por qué preocuparse de ser verdadero; debe extraer del caos los rasgos humanos!" Para Borges, como para Schwob, el tema subyacente es la literatura, ya aparezca como ficción, ensayo o documento, excavando y desenterrando nuevas capas de su propio ser literario, ya que no hay otra cosa. ${ }^{8}$

En el prólogo a una traducción argentina de La cruzdda de los niños, relato de Marcel Schwob, escrito originariamente en 1895, Borges elogia a Schwob por su interpretación imaginativa de un episodio histórico, que permite al lector ver sus muchas dimensiones, el vigor irracional de la historia mientras se está haciendo. También critica Borges el método empírico y científico de los historiadores que no han podido dar "explicaciones de tipo racional, de tipo social, de tipo económico, de tipo étnico" de las Cruzadas, porque el momento histórico en que ocurren es particularmente irracional. En contraste, la minuciosa precisión con que Schwob trata el episodio, tal como él lo concibe imaginativamente, agrega otra dimensión, intensificando en vez de debilitar la cualidad legendaria, conmovedora, de la historia. Incluso Borges apoya el método imaginativo, pero preciso, de Schwob al compararlo con el del historiador Gibbon, quien advirtió que las circunstancias más aparentemente insignificantes son también las más conmovedoras. ${ }^{9}$

Lo que dice Schwob en su prefacio a las Vidas imaginarias refuerza las observaciones de Borges. En el prefacio, él se queja del método uniforme empleado por los biógrafos: sólo escriben las historias de los grandes, sin advertir que las vidas de la gente oscura pueden tener más interés. "El arte se opone a las ideas generales, sólo describe lo individual, sólo desea lo único. No clasifica; desclasifica".

No se crea que estas coincidencias entre Schwob y Borges derivan de una actitud idéntica frente a la materia literaria. El propio Borges se ha encargado de precisar, en una conversación que tuve con él recientemente en Nueva York (dičiembre 9, 1969), que "la concepción de las Vidas imaginarias es superior al libro mismo". También señaló entonces que el mejor relato del libro es el último, dedicado a los Sres. Burke y Hare,

8 James E. Irby: "Preface to two early stories of Borges", en Quarterly Review of Literature (Princeton), XV, Nos. 3/4, Primavera 1968.

9 Jorge Luis Borges: Prólogo a La cruzada de los niños, de Marcel Schwob. Buenos Aires: Editorial Jacinto Alvarez (Colección La Perdiz), 1949. 
asesinos, ya que es el único en que Schwob llega a realizar su concepción. Es el único, podría también agregarse, que ha servido directamente de modelo a estas historias de la infamia que Borges publica en 1935.

El fundamento histórico de la mayor parte de los relatos de Borges es aún más oscuro que el de las narraciones de Schwob. En realidad, muchos de los relatos de este libro de Borges son pura fantasía, apenas apoyada en una semilla de realidad. La crítica que hace Borges de los historiadores es aún más devastadora que la de Schwob, ya que él deliberadamente ignora el método histórico, y prefiere idiosincráticamente un enfoque artístico, similar al de un "cierto director cinematográfico" que relata sus historias a través de "imágenes discontinuas". Aquí Borges alude obviamente a Joseph von Sternberg."

La técnica narrativa de Borges consiste, esencialmente, en el tratamiento de la historia en una forma no cronológica e imaginativa como, por ejemplo, la introducción de personajes de la ficción literaria o de seres reales dentro de la fábrica del relato. García Márquez hará lo mismo al yuxtaponer el coronel Buendía y el Duque de Marlborough, o al introducir en su novela personajes o acontecimientos de otras obras de ficción, empezando por las suyas. Al referirse al entierro de Melquíades en Cien años de soledad, dice:

Fue el primer entierro y el más concurrido que se vio en el pueblo, superado apenas un siglo después por el carnaval funerario de la Mamá Grande. ${ }^{11}$

Este personaje, ya se sabe, pertenece a su cuento, "Los funerales de la Mamá Grande". 12. Otra alusión literaria aparece al narrar la huelga bananera y el consiguiente arresto de los revolucionarios. Aqui el autor colombiano interpola un personaje de una novela contemporánea:

Entre eilos se llevaron a José Arcadio Segundo y a Lorenzo Gavilán, un coronel de la revolución mexicana, exilado en Macondo,

10 "El asesino desinteresado Bill Harrigan", p. 68. La cita completa de Borges es: "La Historia (que, a semejanza de cierto director cinematográfico, procede por imágenes discontinuas)...". En el prólogo a la Historta Universal de la Infamia, p. 7 se reconoce la influencia de "los primeros films de von Sternberg".

11 Op. cit., p. 69.

12 Gabriel García Märquez: Los funerales de la Mamá Grande. México: Universidad de Xalapa, 1962. Hay reedición: Buenos Aires: Editorial Sudamericana, 1967. 
que decía haber sido testigo del heroísmo de su compadre Artemio Cruz. ${ }^{13}$

El lector ya habrá reconocido al protagonista de la novela de Carlos Fuentes La muerte de Artemio Cruz. También se incluyen en Cien años de soledad referencias a personajes de novelas de Alejo Carpentier y Julio Cortázar.

No sólo en estos aspectos exteriores coincide Garcia Márquez con Borges y, hasta cierto punto, con Schwob. Así, por ejemplo, la indistin. ción entre los hechos reales y las fantasías, en los relatos de estos últimos, aparece reflejada en una entrevista con Alfonso Monsalve, en donde dice García Márquez que quiere contar historias interesantes, y aclara:

Historias reales no son, ciertamente, historias documentadas, pero son historias sacadas de mi experiencia vivida. Buscando me he dado cuenta de que la realidad en Latinoamérica, la realidad en que vivimos, en la que nos criamos, la que nos formó, se confunde diariamente con Ia fantasia. ${ }^{14}$

\section{LOS SECRETOS DE UN ESTILO COMÚN}

También en el estilo es posible apuntar importantes coincidencias entre García Márquez y los dos cuentistas estudiados. El estilo de Schwob, como el de Borges, y hasta cierto punto el de Virginia Woolf también, transforma la realidad para enfatizar lo único y singular, lo que les parece, sin duda, lo más significativo aunque desde el punto de vista de la vida cotidiana esos elementos no sean los más obvios o relevantes. La clave del estilo enfático está en el detalle revelador. En vez de emplear un estilo literal y explícito, Schwob, por ejemplo, utiliza palabras significativas, tonos $y_{1}$ metáforas que no sólo presentan otras dimensiones de la historia sino que contribuyen a visualizar, de modo más fuerte de lo que es habitual, la realidad.

Así en la biografía de los Sres. Burke y Hars, Schwob no expone los aspectos más horribles de su carrera de crímenes sino que eufemiza y sati-

I3 Op. cit., p. 254. El episodio de La muerte de Artemio Cruz a que Garcia Márquez se refiere en su texto corresponde al capítulo fechado: "(1913: diciembre 4)", pp. 63-85. México: Fondo de Cultura Económica, 1962.

14 Alfonso Monsalve: "Una entrevista con García Márquez: La novela, anuncio de grandes transformaciones", en El Tiempo, Bogotá, 14 de enero, 1968, p. 4. 
riza sus actos y pensamientos por medio de un estilo, a ratos analítico, a ratos metafórico. De esa manera la realidad aparece velada pero más sugestiva. La infamia de sus acciones se viste de paradoja y originalidad:

En la colaboración de los Sres. Burke y Hare no hay duda de que el poder de invención y simplificación pertenecía sólo al Sr. Burke, pero sus nombres aparecen inseparables en el arte, tan inseparables como los de Beaumont y Fletcher. ${ }^{15}$

La alusión a los dramaturgos ingleses de la época jacobina no hace sino enmascarar estos crímenes, simples y brutales, para los que no se necesitaba, por cierto, ningún poder "de invención y simplificación". Pero al mismo tiempo, al usar esta máscara, Schwob convierte a sus personajes en figuras dramáticas. Siguiendo indudablemente a De Quincey, presenta el asesinato como una de las bellas artes. En su breve biografia, Schwob continúa el paralelo entre los dos asesinos y los dos dramaturgos. Así se refiere al periodo clásico de Burke y Hare (crímenes dentro de casa) y al periodo romántico (asesinatos en la calle, que son presentados como "procedimientos nocturnos en la niebla"). ${ }^{16}$ Otro ejemplo de su arte de la alusión es la descripción de la técnica mortal de estos profesionales. Por lo general, invitan a sus víctimas a tomar un trago de whisky y a conversar un rato. El desconocido, casi siempre una persona sin familia, es persuadido a contar la historia de su vida:

Para interrumpir el relato, el Sr. Hare tenía por costumbre pasar detrás del sofá y aplicar sus dos manos sobre la boca del narrador. En este momento, el Sr. Burke venía a sentarse sobre su pecho. Los dos, manteniendo estas posiciones respectivas, soñaban, inmóviles, en la conclusión de la historia que jamás escucharían. De esta manera, los Sres. Burke y Hare dieron fin a un gran número de relatos que el mundo no conocerá jamás. ${ }^{17}$

Schwob nos hace sonreír macabramente cuando se refiere a que Burke y Hare preferian gente joven a gente vieja porque los jóvenes contaban historias más interesantes. Como ejemplo de un eufemismo típico suyo

15 Marcel Schwob: Vies imaginaires. Paris, G. Crès \& Cie,, 1921. pp. 227-228.

16 Op. cit., pp. 233.

17 Op. cit., pp. 230-31. 
se podría mencionar la expresión "desequipaban al personaje", en vez de "desnudaban al cadáver". 18

Esta manera humorística y elegante de decir cosas horribles capta la atención del lector al tiempo que lo conmueve. La manera irónica de Borges, asimismo una distorsión de la forma normal, o literal, de contar, resulta aún más llamativa ya que el escritor argentino por lo general usa verbos y adjetivos inesperados. En la primera historia de su colección, "El espantoso redentor Lazarus Morell", la palabra "espantoso" establece claramente el tono y la extrañeza de la narración al aparecer como calificativo de "redentor". El uso del oxímoron da mayor relieve al enfoque irónico. Un paralelo del estilo eufemístico con que Schwob cuenta los crímenes de Burke y Hare se puede encontrar en esta historia cuando Borges, en vez de decir llanamente que los peces se comieron a un negro asesinado, dice: "y las tortugas y los barbos del Mississippi recibían la última información". 19 Otro ejemplo del mismo cuento muestra hasta qué extremos lleva Borges este estilo:

El Padre de las Aguas, el Mississippi, el río más extenso del mundo, fue el digno teatro de ese incomparable canalla... Es un río de aguas mulatas; más de cuatrocientos millones de toneladas de fango insultan anualmente el Golfo de Méjico... Tanta basura venerable y antigua ha construido un delta... donde laberintos de barro, de pescaditos muertos y de juncos, dilatan las fronteras y la paz de su fétido imperio. ${ }^{20}$

Una vez más, abunda el oxímoron: "incomparable canalla", "basura venerable y antigua", "fétido imperio". Pero no sólo hay oximoron. También juega Borges con las asociaciones metafóricas inesperadas: "aguas mulatas", para referirse a la mezcla de colores en el río; "insultan", verbo que denota una connotación moral, empleado en un sentido físico; "dilatan las fronteras", voz de connotación épica, le sirve para hablar de la expansión de la mugre del río. Los ejemplos podrían multiplicarse al infinito.

Como Borges, Virginia Woolf también incurre en un estilo elaborado. En Orlando dirá de los juegos del protagonista con una cabeza disecada:

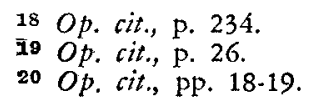


A veces cortaba la cuerda y la cabeza rebotaba en el suelo y tenía que colgarla de nuevo, atándola con cierta hidalguía casi fuera de su alcance, de suerte que su enemigo le hacía muecas triunfales a través de labios contraídos, negros. La cabeza oscilaba de un lado a otro... ${ }^{21}$

La autora proyecta una visión de un objeto, la cabeza, como si éste fuera un sujeto. El mismo recurso se encuentra en Borges cuando juega con la ambigüedad entre objeto y sujeto al hablar de que el protagonista de su cuento, estaba "fumando pensativos cigarros". ${ }^{22}$ La traslación es demasiado clara para necesitar mayor comentario.

Los recursos estilísticos de Borges son numerosos. Tiende a usar y abusar del arte, tan británico, de la alusión, que ya hemos visto practica también Schwob. Para decir que Morell se negaba a ser retratado (y por razones obvias, dada su carrera criminal), dirá Borges: "se negó a la placa bruñida".23 También incurre en la enumeración que le permite decir en forma elaborada algo simple, pero que, sobre todo, impregna de ironía hasta las palabras más inocentes: Así no dirá que un esclavo de Morell fue muerto y arrojado al río, sino: que sus secuaces lo libraron

de la vista, del oído, del tacto, del día, de la infamia, del tienpo, de los bienhechores, de la misericordia, del aire, de los perros, del universo, de la esperanza, del sudor y de él mismo..24

En Cien años de soledad, García Márquez usa también la enumeración, aunque las suyas no son tan sintéticamente indirectas como las de Borges sino que incurren en la hipérbole, característica sobresaliente de su estilo. Así, por ejemplo, hablará en un pasaje de

putas inverosímiles, hembras babilónicas adiestradas en recursos inmemoriales, y provistas de toda clase de ungüentos y dispositivos para estimular a los inermes, despabilar a los tímidos, saciar a los voraces, exaltar a los modestos, escarmentar a los múltiples y corregir a los solitarios. ${ }^{25}$

\footnotetext{
21 Op. cit., p. 11. En la edición norteamericana, el texto está en la p. 14.

22 Op. cit. p. 27.

23 Op. cit., p. 21.

24 Op. cit., pp. 25-26.

25 Op. cit., p. 197.
} 
En otras ocasiones, la enumeración es más discreta pero no menos eficaz. Así, cuando Aureliano trata de disimular su agitación en presencia de Amaranta Ursula, el autor escribe que "atrapó la voz que se le fugaba, la vida que se le iba, la memoria que se le convertía en un pólipo petrificado". ${ }^{26}$

El uso inesperado del lenguaje y su retórica en Schwob, como en Borges y García Márquez, contamina una realidad convencional, o cotidiana, con un sentido inquietante del cambio súbito, de la irrupción de la fantasía, así sea sólo verbal. Así como el lenguaje aparece liberándose de las reglas convencionales; así como ningún sentido de una palabra es más sagrado que otro, del mismo modo la realidad ya no tiene por qué seguir un camino familiar y único.

Por el camino de la fantasía estilística y de la libertad retórica, tanto Marcel Schwob como Jorge Luis Borges han indicado una solución al dilema planteado por la narración realista, y han proporcionado un modelo (breve) de "biografía imaginaria" que el Orlando de Virginia Woolf no haría sino ampliary y explicitar para García Márquez. El ejemplo conjunto de la novelista inglesa y de los dos cuentistas estudiados facilita el modelo biográfico que está en el origen de Cien años de soledad. Lo que habría de agregar García Márquez a este modelo seria, precisamente, la clave de su arte de novelista: la metamorfosis de la biografía del Coronel Buendía en la saga familiar, la apertura del enfoque puramente individual hasta abarcar el linaje entero, la nación y sus mitos. Esa metamorfosis certifica la invención narrativa central de García Márquez.

Columbia University.

SUZANNE JiLl LEVINE

26. Op. cit., p. 330 . 
